\title{
Collaborative Governance dalam Pembudayaan Etika Berlalu-Lintas Pelajar SMA di Kota Yogyakarta
}

\author{
Sugi Rahayu dan Utami Dewi \\ Jurusan Ilmu Administrasi Negara Fakultas Ilmu Sosial \\ Universitas Negeri Yogyakarta \\ Email: sugirahayu@uny.ac.id dan utami.dewi@uny.ac.id
}

\begin{abstract}
Abstrak
Kecelakaan lalu lintas di Kota Yogyakarta terus mengalami kenaikan setiap tahun. Kecelakan ini disebabkan salah satunya karena factor manusia yang tidak mematuhi etika berlalu lintas. Artikel ini bertujuan untuk mendeskripsikan kolaborasi tata kelola pemerintahan yang terjalin antar pemangku kepentingan dalam pembudayaan etika berlalu lintas pelajar SMA di Kota Yogyakarta. Metode yang digunakan adalah deskriptif kualitatif, dengan pengumpulan data melalui Focus Group Discussion, wawancara, observasi dan dokumentasi. Informan dalam penelitian ini adalah Dinas Pendidikan, Pemuda dan Olahraga Daerah Istimewa Yogyakarta, Dinas Perhubungan, Direktorat Lalu Lintas Kepolisian Daerah Istimewa Yogyakarta, Satuan Polisi Lalu Lintas Resort Kota Yogyakarta, Sekolah (SMA Muhammadiyah 3 dan SMA 4 Yogyakarta), keluarga dan peserta didik. Temuan dari penelitian menunjukkan bahwa collaborative governance telah berjalan sesuai dengan teori Ansell dan Gash (2007). Antar actor sudah saling berkomunikasi secara rutin dalam menyusun dan implementasi kegiatan pembudayaan etika berlalu lintas. Selain itu, kolaborasi juga sudah melibatkan unsure nonpemerintah/swasta yaitu PT Astra Honda Motor (AHM) yang dengan memanfaatkan corporate social responsibility melakukan integrasi pendidikan etika berlalu lintas ke dalam kurikulum pembelajaran disekolah. Selain itu pelaksanaan Sekolah Model Pendidikan Etika Berlalu Lintas yang merupakan kolaborasi antara Dinas Pendidikan Kota Yogyakarta, sekolah dan Kepolisian merupakan contoh nyata collaborative governance tersebut.
\end{abstract}

Kata kunci: collaborative governance, etika berlalu lintas, pembudayaan, pelajar SMA

\begin{abstract}
Traffic accidents in Yogyakarta City continue to increase every year. This accident is caused one of them by human factor that does not adhere to the driving ethiquette. This article aims to describe the collaborative governance among stakeholders in the ethical culture of high school students in Yogyakarta. The method used was descriptive qualitative, with data collection through Focus Group Discussion, interview, observation and documentation. The informants in this study were the Yogyakarta Education, Youth and Sports Department, the Transportation Office, the Yogyakarta Provincial Police Traffic Directorate, the Yogyakarta Resort Traffic Police Unit, senior high schools (SMA Muhammadiyah 3 and SMA 4 Yogyakarta), the family and the senior high students. The findings of the research indicated that collaborative governance has proceeded in accordance with the theory of Ansell and Gash (2007). Inter actor communicate with each other regularly in preparing and implementating of ethical culture activities in traffic. In addition, the collaboration also involves non-government / private elements, namely PT Astra Honda Motor (AHM) by utilizing corporate social responsibility to integrate ethical education
\end{abstract}


into the school curriculum of learning. In addition, the implementation of the School of CrossEthics Education Model which is a collaboration between the Education Department of Yogyakarta City, the school and the Police is a real example of collaborative governance.

Keywords: collaborative governance, ethics of traffic, culture, high school students

\section{Pendahuluan}

Pelanggaran terhadap etika berlalu lintas menjadi salah satu faktor penyebab kecelakaan lalu lintas. Faktor manusia yang lalai terhadap aturan tertib berlalu lintas merupakan cermin dari perilaku ketidakdisiplinan masyarakat. Berbagai macam contoh pelanggaran seperti tidak mematuhi rambu lalu lintas dan tidak menggunakan alat keselamatan lalu lintas menunjukkan rendahnya tingkat kedisiplinan masyarakat dalam berkendara, sehingga melahirkan budaya tidak disiplin pada masyarakat.

Di Kota Yogyakarta angka kecelakaan dari tahun ke tahun terus bertambah. Data Unit Kecelakaan Lalu Lintas Satuan Lalu lintas Yogyakarta Polresta Yogyakarta hingga akhir 2015, tercatat terjadi peningkatan mencapai 32 persen dari tahun 2014 (http://jogja.tribunnews.com/2015/12/21/). Data tentang kecelakaaan dari tahun 2013 sampai 2015 adalah seperti terlihat dalam Tabel 1 berikut ini:

Tabel 1. Jumlah Kecelakaan Lalu Lintas di Kota Yogyakarta Tahun $2013-2015$

\begin{tabular}{|l|c|c|}
\hline NO & TAHUN & JUMLAH \\
\hline 1. & 2013 & 528 \\
\hline 2. & 2014 & 496 \\
\hline 3. & 2015 & 636 \\
\hline
\end{tabular}

Sumber: Satuan Polisi Lalu Lintas, 2015

Kecelakaan ini sebagian besar terjadi karena faktor manusia yang kurang memahami arti pentingnya etika berlalu lintas. Pada umumnya kecelakaan terjadi apabila pengendara lalai dalam berkendara dan melakukan pelanggaran terhadap aturan-aturan berkendaraan yang berlaku. Tingginya angka pelanggaran lalu lintas di Yogyakarta menunjukkan kesadaran masyarakat akan keselamatan dan ketaatan dalam berlalu lintas di Kota Yogyakarta masih rendah. Pengendara sepeda motor memiliki risiko lebih besar apabila terjadi kecelakaan. Oleh karena itu perhatian masyarakat dalam etika berlalu lintas sangat diperlukan demi keselamatan bersama. 
Data yang dikeluarkan oleh World Health Organization (WHO) pada tahun 2015 menyebutkan bahwa Indonesia menduduki peringkat kelima di dunia dalam jumlah kematian akibat kecelakaan lalu lintas. Setiap hari tercatat sejumlah 120 jiwa meninggal akibat kecelakaan lalu lintas. Data yang lebih mencengangkan adalah bahwa Indonesia menempati urutan pertama di dunia dalam peningkatan kecelakaan menurut data Global Status Report on Road Safety yang dikeluarkan WHO. Indonesia dilaporkan mengalami kenaikan jumlah kecelakaan lalu lintas hingga lebih dari 80 persen (www.republika.co.id, tanggal 06 November 2014). Jumlah korban meninggal dunia pada tahun 2015 di Kota Yogyakarta akibat kecelakaan lalu lintas juga mengalami peningkatan seperti dapat dilihat pada tabel 2 berikut ini.

Tabel 2. Jumlah Kematian dan Kerugian Materiil Akibat Kecelakaan Lalu lintas di Kota Yogyakarta Tahun 2013-2015

\begin{tabular}{|c|c|r|r|}
\hline NO & TAHUN & \multicolumn{1}{|c|}{$\begin{array}{c}\text { JUMLAH } \\
\text { KEMATIAN }\end{array}$} & \multicolumn{1}{c|}{$\begin{array}{c}\text { KERUGIAN } \\
\text { MATERIIL (Rp) }\end{array}$} \\
\hline 1 & 2013 & 32 & 1.035 .100 .000 \\
\hline 2 & 2014 & 42 & 936.250 .000 \\
\hline 3 & 2015 & 46 & 482.261 .000 \\
\hline \multicolumn{2}{|c|}{ Jumlah } & 120 & 2.453 .611 .000 \\
\hline
\end{tabular}

Sumber: Tribunjogja, 21 Desember 2015

Tabel 2 menunjukkan bahwa dari tahun 2013 sampai akhir tahun 2015 tercatat korban meninggal akibat kecelakaan lalu lintas di Kota Yogyakarta mengalami peningkatan. Korban akibat kecelakaan didominasi oleh usia produktif, antara usia 15 tahun hingga 30 tahun. Sedangkan untuk kerugian materi akibat kecelakaan dari tahun 2013 sampai tahun 2015 mengalami penurunan. Dalam hal ini AKP Hendro mengungkapkan, penyebab utama terjadinya kecelakaan lalu lintas merupakan pelanggaran terhadap aturan lalu lintas yang dilakukan oleh pengguna jalan (Tribunjogja.com, 21 Desember 2015).

Pemerintah sebenarnya telah berupaya mengurangi angka kecelakaan yang bersumber dari faktor manusia dengan mengeluarkan sejumlah kebijakan. Di Kota Yogyakarta Walikota Kota Yogyakarta telah mengeluarkan Peraturan Walikota Yogyakarta Nomor 40 Tahun 2012 tentang Pelaksanaan Pendidikan Etika Berlalu Lintas di Kota Yogyakarta. Kebijakan ini disusun dengan maksud sebagai pedoman bagi satuan pendidikan dalam melaksanakan pendidikan etika berlalu lintas. Adapun tujuan pendidikan etika berlalu lintas adalah untuk: 1) menumbuhkembangkan norma-norma etika berlalu lintas bagi peserta didik melalui pengembangan pengetahuan, serta pembiasaan tentang etika berlalu lintas; 2) meningkatkan 
ketertiban dan kelancaran dalam berlalu lintas; dan 3) meningkatkan keselamatan dan kenyamanan berlalu lintas (Pasal 2 Perwal No 40 Tahun 2012).

Pelaksanaan pendidikan etika berlalu lintas tidak hanya menjadi tugas pemerintah saja. Pihak lain seperti keluarga, peserta didik, sekolah, swasta, lembaga swadaya masyarakat dan tokoh masyarakat juga dapat berperan dalam pelaksaan etika berlalu lintas. Kolaborasi berbagai aktor ini sangat dibutuhkan agar pelaksanaan pendidikan etika berlalu lintas dapat berjalan dengan maksimal. Kolaborasi antar aktor baik pemerintah, swasta maupun masyarakat dalam merumuskan kebijakan atau melaksanakan suatu kebijakan dan program sering disebut sebagai collaborative governance. Secara lebih rinci Ansell dan Gash (2007: 544) mendefinisikan collaborative governance sebagai:

A governing arrangement where one or more public agencies directly engage non-state stakeholders in a collective decision-making process that is formal, consensus-oriented, and deliberative and that aims to make or implement public policy or manage public programs or assets.

Lebih lanjut Ansell dan Gash (2007) menyatakan bahwa terdapat 6 (enam) kriteria dari collaborative governance ini yaitu: 1) forum diprakarsai oleh badan publik atau institusi, (2) peserta dalam forum termasuk aktor non-negara, (3) peserta terlibat langsung dalam pengambilan keputusan dan tidak hanya "dikonsultasikan" oleh badan publik, (4) forum diatur secara formal dan bertemu secara kolektif, (5) forum bertujuan untuk membuat keputusan dengan konsensus (bahkan jika konsensus tidak tercapai dalam praktik), dan (6) fokus kolaborasi ada pada kebijakan publik atau manajemen publik. Dalam pelaksanaan pendidikan etika berlalu lintas di Kota Yogyakarta sejumlah aktor terlibat yaitu: 1) Pemerintah (Dinas Pendidikan Pemuda dan Olahraga; Dinas Perhubungan; Dinas Perindustrian; Dinas Komunikasi dan Informasi; dan Kepolisian; 2) Sekolah; 3) Swasta dan perindustrian; 4) Keluarga, 5) masyarakat dan 6) PT jasa Raharja dan BPS.

Artikel ini bertujuan untuk mendeskripsikan kolaborasi antar aktor dalam pembudayaan etika berlalu lintas pelajar Sekolah Menengah Atas di Kota Yogyakarta. Pada bagian awal penulis akan menjelaskan bagaimana kolaborasi antar aktor terbangun dalam pembudayaan etika berlalu lintas sementara pada bagian kedua akan menjelaskan factor penghambat pembudayaan etika berlalu lintas tersebut. Terakhir, penulis menekankan bahwa kolaborasi governance ini masih perlu ditingkatkan melalui berbagai macam inovasi kegiatan 
sehingga budaya tertib berlalu lintas akan terinternalisasi dalam jiwa para pelajar SMA yang sedang dalam mencari jati diri dan ingin selalu tampil berbeda dari kelompok masyarakat lainnya.

\section{Metode}

Artikel ini dihasilkan dari penelitian dengan desain deskriptif kualitatif. Data diperoleh melalui Focus Group Discussion, wawancara, dokumentasi dan observasi. Informan sebagai sumber data meliputi Dinas Pendidikan, Pemuda dan Olahraga Daerah Istimewa Yogyakarta, Dinas Perhubungan, Direktorat Lalu Lintas Kepolisian Daerah Istimewa Yogyakarta, Satuan Polisi Lalu Lintas Resort Kota Yogyakarta, Sekolah (SMA Muhammadiyah 3 dan SMA 4 Yogyakarta), keluarga dan peserta didik. Teknik pengecekan keansahan data menggunakan triangulasi sumber sementara teknik analisis data menggunakan metode interaktif Miles dan Huberman (dalam Sugiyono, 2010) yang terdiri dari pengumpulan data, reduksi data, display data, verifikasi data dan penarikan kesimpulan.

\section{Hasil dan Pembahasan}

\section{Collaborative Governance dalam Pembudayaan Etika Berlalu Lintas Pelajar SMA}

Dalam pembudayaan etika berlalu lintas kolaborasi terjalin baik antar pemerintah, swasta dan masyarakat selaku pemangku kepentingan (stakeholders). Masing-masing pihak yang terlibat memiliki kewenangan yang dapat saling mendukung dalam menciptakan budaya tertib berlalu lintas. Pemangku kepentingan dalam pembudayaan etika berlalulintas merujuk partisipasi warga sebagai individu dan partisipasi masyarakat secara lebih luas Selain itu collaboratif governance ini juga merujuk. pada lembaga publik dan pemangku kepentingan non-negara (Ansell dan Gash, 2007). Kolaborasi menyiratkan komunikasi dua arah dan pengaruh antara keduanya dan juga kesempatan bagi pemangku kepentingan untuk berbicara dengan masing-masing pihak lain. Instansi dan pemangku kepentingan harus bertemu bersama melalui proses deliberatif dan multilateral.

Dalam pembudayaan etika berlalu lintas pelajar SMA di Kota Yogyakarta, aktor yang terlibat adalah dari pihak pemerintah (Dinas Pendidikan, Pemuda dan Olahraga Daerah Istimewa Yogyakarta, Dinas Perhubungan, Direktorat Lalu Lintas Kepolisian Daerah Istimewa Yogyakarta, Satuan Polisi Lalu Lintas Resort Kota Yogyakarta, Dinas Perhubungan, Dinas 
Perindustriandan Dinas Kominfo), Badan Penyelenggara Jaminan Asuransi (BPJS), Swasta (AHM Honda), Sekolah, keluarga dan peserta didik.

\section{a. Pemerintah}

\section{1) Dinas Pendidikan Pemuda dan Olahraga Daerah Istimewa Yogyakarta}

Menurut Undang-undang Nomor 22 Tahun 2009 tentang Lalu Lintas dan Angkutan jalan, khususnya dalam Pasal 208 Ayat 2 menyatakan bahwa untuk membangun dan mewujudkan budaya Keamanan dan Keselamatan Lalu Lintas dan Angkutan Jalan dapat dilakukan melalui pelaksanaan pedidikan berlalu lintas sejak usia dini, serta adanya sosialisasi dan internalisasi tata cara dan etika berlalu lintas serta program Keamanan dan Keselamatan Lalu Lintas dan Angkutan Jalan. Pendidikan etika lalu lintas (Pasal 1 Ayat (1) Pergub DIY 54/2011) adalah penanaman budaya tertib berlalu lintas yang dimulai dari pembiasaan-pembiasaan di satuan pendidikan. Selain itu berdasarkan Peraturan Walikota Nomor 40 Tahun 2012 Tentang Pendidikan Etika Berlalu Lintas dapat diketahui bentuk dan ruang lingkup pendidikan etika lalu lintas adalah meliputi:

(a) Pengintegrasian etika berlalu lintas dalam mata pelajaran

Pengintegrasian merupakan suatu proses penyatuan materi etika berlalu lintas ke dalam mata pelajaran yang menjadi bagian dari kompetensi dasar. Dalam pelaksanaan pengintegrasian, pendidik melakukan analisis pemetaan Standar Kompetensi/Kompetensi Dasar dengan memperhatikan Standar Isi dan Standar Kompetensi Lulusan (SKL). Hasil analisis pemetaan ditindaklanjuti dalam pengembangan Silabus dan Rencana Pelaksana Pembelajaran (RPP). Tata cara penyusunan analisis pemetaan ditetapkan dengan keputusan kepala dinas.

(b) Pengembangan diri dan budaya satuan pendidikan

Pengembangan diri dalam pendidikan etika berlalulintas dapat dilaksanakan melalui program pembiasaan dan atau kegiatan ekstrakurikuler di satuan pendidikan. Pembiasaan dilaksanakan melalui penanaman nilai-nilai ketaladanan, kedisiplinan, tanggung jawab, dan kepedulian lingkungan. Kegiatan ekstrakurikuler dilaksanakan melalui patroli keamanan sekolah, kepramukaan dan kegiatan ekstrakurikuler lainnya yang berkaitan. Pengembangan diri dalam pendidikan etika berlalulintas 
dilaksanakan oleh seluruh warga satuan pendidikan dengan dukungan dari masyarakat (Furi Romzah, 2014)

(c) Pedoman penilaian etika berlalu lintas

Penilaian etika berlalu lintas sebagaimana dilaksanakan pada waktu proses pembelajaran, dan atau akhir kegiatan pembelajaran. Penilaian etika berlalu lintas dilaksanakan oleh pendidik, masyarakat satuan pendidikan, dan atau pemangku kepentingan. Penilaian etika berlalu lintas yang meliputi aspek pengetahuan, keterampilan, dan sikap dilakukan dengan cara tes dan nontes. Hasil penilaian etika berlalu lintas menjadi salah satu pertimbangan dalam pengambilan keputusan nilai kepribadian peserta didik.

Berkaitan dengan tiga bentuk pendidikan etika berlalu lintas tersebut, Dinas Pendidikan, Pemuda dan Olahraga telah melaksanakan berbagai macam program yaitu:

(a) Bekerja sama dengan Direktorat Lalu Lintas Polda DIY menyelenggarakan sekolah Model Pendidikan Etika Berlalu Lintas sejak tahun 2013. Penunjukan sekolah model ini berdasarkan Keputusan Gubernur Provinsi DIY NOmor 222/KEP/2013 tentang Penetapan Sekolah Model Pendidikan Etika Berlalu Lintas. Beberapa sekolah menengah atas di Kota Yogyakarta terpilih sebagai sekolah model etika berlalu lintas diantaranya SMAN 5 Yogyakarta, SMAN 6 Yogyakarta, SMAN 8 Yogyakarta, SMA Muhammadiyah 3 Yogyakarta, SMA Muhammadiyah 7 Yogyakarta, SMKN 2 Yogyakarta, SMKN 4 Yogyakarta, SMKN 5 Yogyakarta dan SMKN 6 Yogyakarta.

(b) Memasukkan nilai etika berlalu lintas dalam kurikulum pembelajaran Nilai-nilai etika berlalu lintas termasuk materi rambu-rambu lalu lintas dimasukkan dalam mata pelajaran Pendidikan Kewarganegaraan (PKn).

(c) Monitoring ke sekolah-sekolah di Kota Yogyakarta untuk memonitor dan evaluasi pelaksanaan kurikulum pendidikan etika berlalu lintas.

\section{2) Direktorat Lalu Lintas Polda DIY dan Satuan Polisi Lalu Lintas Kota Yogyakarta} Sebagai actor utama dalam pembudayaan etika berlalu lintas, Direktorat Lalu Lintas (Ditlantas) dan Satuan Polisi Lalu Lintas Kota Yogyakarta telah melaksanakan sejumlah kegiatan yaitu: 
(a) Sosialisasi tertib lalu lintas dan safety riding pada beberapa sekolah menengah atas di Kota Yogyakarta secara rutin

Kegiatan sosialisasi tertib berlalu lintas dan safety riding dilaksanakan pada sekolah menengah atas secara bergiliran di seluruh Kota Yogyakarta. Peserta kegiatan sosialisasi adalah para siswa sekolah yang dituju.

(b) Pembina upacara dan sosialisasi etika berlalu lintas

Kegiatan ini dilakukan secara bergiliran di SMA di Kota Yogyakarta. Dengan menjadi Pembina upacara bendera hari senin, pihak kepolisian dapat melakukan sosialisasi etika berlalu lintas kepada seluruh guru dan siswa.

(c) Pelaksanaan program Satu Sekolah Dua Polantas (SSDP)

Pada bulan Desember 2012 Daerah Istimewa Yogyakarta menjadi daerah pertama yang melaksanakan Program Satu Sekolah Dua Polantas (SSDP). Program ini ditujukan untuk meningkatkan pengetahuan dan wawasan berlalulintas. Selain itu melalui SSDP juga diharapkan mampu menekan sejumlah potensi kenakalan remaja termasuk mencegah kecelakaan lalu lintas dan juga peredaran narkoba.

(d) Melaksanakan bimbingan dan penyuluhan kepada siswa yang terlambat datang ke sekolah

(e) Melakukan kegiatan diseminasi kepada Guru mata pelajaran PKN di Kota Yogyakarta untuk mengikuti diseminasi di tingkat Provinsi tentang internalisasi kurikulum pendidikan etika berlalu lintas pada pelajaran PKn. Kegiaatn ini pada tahun 2016 telah dilaksanakan pada tanggal 1 Desember 2016 di Hotel Rich Yogyakarta.

(f) Koordinasi dengan Dinas Pendidikan dan Olahraga DIY tentang pelaksanaan diseminasi dan verifikasi terhadap sekolah model pendidikan etika berlalu lintas yang telah dutetapkan oleh Gubernur DIY Nomor 222/KEP/2013 tanggal 26 Agustus 2013 tentang Penetapan Sekolah Model Pendidikan Etika Berlalu Lintas.

\section{3) Dinas Perhubungan}

Dinas Perhubungan merupakan unsur pemerintah yang mempunyai tugas dan kewenangan untuk penyediaan sarana berlalu lintas dan alat penunjang informasi berlalu lintas (APILL). Selain itu Dinas Perhubungan juga berperan dalam melakukan edukasi tentang tertib berlalu lintas kepada anak atau siswa mulai PAUD sampai 
dengan dewasa melalui pembangunan Taman Lalu Lintas di Terminal Bis Giwangan Kota Yogyakarta.

\section{4) Dinas Pekerjaan Umum}

Dinas Pekerjaan Umum berperan dalam pembangunan dan renovasi jalan. Faktor jalan/fisik (jalan berlubang atau bergelombang) juga menjadi salah satu penyebab kecelakaan lalu lintas selain faktor manusia yang melakukan pelanggaran etika berlalu lintas.

\section{5) Dinas Perindustrian}

Dinas Perindustrian mempunyai peran dalam menyediakan peralatan keselamatan berlalu lintas seperti helm berstandar SNI dan peralatan/onderdil kendaraan bermotor. Saat ini Dinas Perindustrian dan Kepolisian bekerja sama dalam melakukan kampanye safety riding melalui penggunaan helm berstandar nasional dan kelengkapan berkendara seperti spion dan lampu sepeda motor.

\section{6) Dinas Komunikasi dan Informasi}

Dari unsur pemerintah, Dinas Komunikasi dan Informasi juga sangat berperab dalam mendukung pembudayaan etika berlalu lintas. Dinas ini menjadi garda depan dalam melakukan sosialisasi dan diseminasi kebijakan-kebijakan pemerintah terkait pendidikan etika berlalu lintas.

\section{b. Sekolah}

Pihak sekolah merupakan aktor kunci dalam collaborative governance pembudayaan etika berlalu lintas. Sekolah mempunyai peran dalam pembudayaan etika berlalu lintas melalui beberapa kegiatan yaitu:

1) Integrasi pendidikan etika berlalu lintas pada setiap mata pelajaran khususnya Pendidikan Kewarganegaraan (PKn) yang dapat terlihat melalui penyusunan silabus dan Rencana Proses Pembelajaran (RPP).

2) Integrasi pendidikan etika berlalu lintas dalam kehidupan sehari-hari di sekolah

3) Bekerja sama dengan keluarga siswa melalui penerapan budaya tertib lalu lintas dalam kegiatan sehari-hari di rumah sehingga tercipta harmoni antara pembiasaan etika berlalu lintas di sekolah dan dirumah.

Pembudayaan etika lalu lintas di Kota Yogyakarta, khususnya SMA 4 Yogyakarta dan SMA Muhammadiyah 3 Yogyakarta yang menjadi subjek penelitian dalam penelitian ini, 
dilaksanakan melalui pengintegrasian kedalam mata pelajaran, budaya sekolah dan pengembangan diri. Pengintegrasian pendidikan etika lalu lintas dalam mata pelajaran, dilakukan dengan cara memasukkan etika lalu lintas ke dalam silabus dan RPP yang relevan dengan materi. Pendidikan etika lalu lintas ke dalam budaya sekolah dilakukan melalui kegiatan rutin, keteladanan dan pengkondisian. Sedangkan dalam pengembangan diri dilakukan melalui kegiatan ekstrakurikuler Patroli Keamanan Sekolah atau PKS, PMR, dan Pramuka. Selain itu sekolah juga telah melarang siswa yang belum memiliki SIM untuk membawa sepeda motor ke sekolah dan memberikan peringatan bagi siswa yang melanggar aturan ini.

Pada tanggal 15 September 2015, SMA Muhammadiyah 3 Yogyakarta, menyelenggarakan In House Training (IHT) tentang Sekolah Model Pendidikan Etika Berlalu Lintas. Peserta IHT, terdiri dari seluruh Pendidik dan Tenaga Kependidikan, serta perwakilan dari Peserta Didik. Diihadiri juga dari Kepolisian Sektor Wirobrajan, Koramil Wirobrajan, serta Komite Sekolah. Nara sumber dalam kegtiatan ini adalah Tim Pengembangan Sekolah Model Pendidikan Etika Berlalu Lintas Dinas Pendidikan Kota Yogyakarta.

\section{c. Swasta}

Kolaborasi tata kelola pembudayaan etika berlalu lintas juga sangat didukung dengan peran pihak swasta melalui corporate social responsibility (CSR). Salah satu bentuk kepedulian swasta dilakukan oleh PT Astra Honda Motor (AHM) terhadap dunia pendidikan yaitu dengan berkomitmen rutin mengkampanyekan safety riding kepada setiap pelanggan motor Honda. Program ini merupakan implementasi tanggung jawab sosial perusahaan dalam mendukung upaya mengurangi potensi kecelakaan lalu lintas di masyarakat. Bekerjasama dengan instansi pemerintah, yaitu Dinas Pemuda dan Olahraga serta Polda DIY, AHM berkomitmen terhadap kesadaran berkendara, mengingat perusahaan ini mendominasi pasar sepeda motor di Indonesia.

Bekerjasama dengan PT AHM, Dinas Pendidikan Kota Yogyakarta pada tahun 2012 membentuk inisiatif dengan membuat "Model Integrasi Kurikulum Pendidikan Etika Berlalu Lintas" di kota Yogyakarta. Kolaborasi tersebut menjadi penting karena Dinas Pendidikan Kota Yogyakarta sebagai pihak yang memiliki dan menguasai data objek 
sasaran sehingga hubungan kerjasama tersebut dapat menumbuhkan kekuatan, melengkapi strategi dan kapabilitas yang tidak dimiliki oleh perusahaan. Dalam hal ini, Dinas Pendidikan kota Yogyakarta yang memiliki kapasitas seutuhnya akan informasi dan pengetahuan mengenai pendidikan terutama perihal kurikulum. Selain itu, AHM juga mendapatkan anugerah dari Museum Rekor Indonesia (MURI) sebagai Pelopor Implementasi Sekolah Model Budaya Etika Lalu Lintas. Fenomena ini menjadi unik di mana AHM sebagai perusahaan otomotif yang pertama masuk di bidang kurikulum pendidikan dalam program CSR, bahkan beberapa kompetitor dalam industri sepeda motor belum ada yang menyentuh ranah kurikulum pendidikan (Antaranews, diakses pada tanggal 8 Oktober 2017).

\section{d. PT Jasa Raharja dan Badan Penyedia Jaminan Kesehatan (BPJS)}

Selain aktor-aktor di atas, collaborative governance dalam pembudayaan etika berlalu lintas juga sangat membutuhkan peran PT Jasa Raharja dan BPJS sebagai penyedia layanan asuransi berkendara dan kesehatan.

\section{e. Keluarga dan masyarakat}

Kehadiran keluarga menjadi penentu atau aktor terpenting dalam pembudayaan etika berlalu lintas. Keluarga sangat berperan dalam membentuk kedisiplinan dan kebiasaan budaya tertib berlalu lintas. Namun demikian, keluarga juga sebaliknya bisa menjadi actor yang mendukung pelanggaran tertib berlalu lintas ketika membiarkan anakanak atau anggota keluargayang belum memiliki surat ijin mengemudi diperbolehkan membawa sepeda motor ke sekolah. Tentunya pembiasaan ini bertentangan dengan pembudayaan etika berlalu lintas yang telah ditempuh oleh pemerintah dan sekolah. Selain keluarga, masyarakat juga sangat berperan dalam memonitor dan mengevaluasi penerapan kurikulum pendidikan etika berlalu lintas yang telah diintegrasikan melalui pembelajaran di sekolah dan di rumah.

Ketujuh aktor tersebut berkolaborasi dan berperan dalam pembudayaan etike berlalu lintas. Masing-masing actor memiliki tugas dan wewenang sendiri dan kemudian para stakeholders tersebut saling berkomunikasi dalam membuat suatu program atau kegiatan, mengimplementasikan dan mengevaluasi program pendidikan etika berlalu lintas. Keluarga memegang peran kunci dalam pembiasaan dan memelihara budaya tertib 
berlalu lintas melalui kegiatan sehari-hari dirumah. Bahkan keluarga lah yang berhak memberikan izin kepada siswa untuk boleh naik sepeda motor atau belum saat belum punya surat ijin mengemudi/ SIM. Oleh karena itu, kolaborasi antar aktor tersebut perlu terus diperkuat agar pembudayaan etika berlalu lintas dapat berjalan secara optimal untuk menekan angka kecelakaan lalu lintas karena faktor manusia.

\section{Faktor Penghambat Pembudayaan Etika berlalu lintas}

Dalam pembudayaan etika berlalu lintas, terdapat kendala collaborative governance yang menyebabkan pelaksanaan pembudayaan etika berlalu lintas kurang optimal. Adapun factor penghambat tersebut adalah:

a. Kurangnya sumber daya manusia dari pihak kepolisian dalam menjalankan program Satu Sekolah Dua Polantas (SSDP).

b. Kurangnya kesadaran orang tua untuk melarang anak (yang belum memiliki SIM) mengendarai sepeda motor ke sekolah dengan alasan sibuk bekerja.

c. Kurangnya kesadaran masyarakat dalam mendukung pembudayaan pendidikan etika berlalu lintas. Hal ini dapat terlihat dari masih beroperasinya tempat parker sepeda motor di dekat sekolah untuk menampung siswa yang belum memiliki SIM tetapi tetap mengendarai sepeda motor ke sekolah.

Dari pemangku kepentingan yang terlibat dalam pembudayaan etika berlalulintas, dapat terlihat bahwa collaborative governance seperti yang diungkapkan oleh Ansell dan Gash (2007) yaitu ada 6 syarat utama meliputi:

a. Forum diprakarsai oleh badan publik atau institusi,

Collaborative governance dalam pembudayaan etika berlalu lintas bagi pelajar SMA di Kota Yogyakarta melibatkan Polda DIY, Polres Kota Yogyakarta, Dinas Pendidikan, Pemuda dan Olahraga DIY sebagai institusi publik.

b. Peserta dalam forum termasuk aktor non-negara

Collaborative governance melibatkan Honda AHM motor sebagai pemangku kepentingan yang berasal dari swasta.

c. Peserta terlibat langsung dalam pengambilan keputusan dan tidak hanya "dikonsultasikan" oleh badan publik. Kegiatan pembudayaan etika berlalu lintas bagi 
pelajar SMA di Kota Yogyakarta disusun dan diimplementasikan oleh pemangku kepentingan dalam collaborative governance ini.

d. Forum diatur secara formal dan bertemu secara kolektif

Aktor dan pemangku kepentingan yang terlibat dalam kegiatan pembudayaan etika berlalu lintas bagi pelajar di Kota Yogyakarta melakukan koordinasi dan pertemuan rutin.

e. Forum yang terbangun untuk pembudayaan etika berlalu lintas bertujuan untuk membuat keputusan dengan konsensus

f. Fokus kolaborasi pembudayaan etika berlalu nlintas bagi pelajar SMA di Kota Yogyakarta ini adalah sebagai bentuk implementasi Undang-undang Nomor 22 Tahun 2009 tentang Lalu Lintas dan Angkutan Jalan; Peraturan Gubernur DIY Nomor 222/KEP/2013 tanggal 26 Agustus 2013 tentang Penetapan Sekolah Model Pendidikan Etika Berlalu Lintas.

\section{Simpulan}

Berdasarkan hasil pembahasan di atas dapat disimpulkan bahwa collaborative governance dalam pembudayaan etika berlalu lintas bagi pelajar SMA di Kota Yogyakarta telah berjalan sesuai dengan kriteria Ansell dan Gash (2007). Bahkan Kota Yogyakarta mencatat sejumlah prestasi di tingkat nasional sebagai pioneer dalam implementasi kurikulum pendidikan etika berlalu lintas yang telah dilaksanakan sejak tahun 2013 dengan kolaborasi antara PT Astra Honda Motor (AHM) dan Dinas Pendidikan Kota Yogyakarta. Selain itu kolaborasi antara Dinas Pendidikan Pemuda dan Olahraga (Disdikpora) DIY dan Kepolisian juga terjalin dengan baik melalui kegiatan diseminasi dan verifikasi Sekolah Model Pendidikan Etika Berlalu lintas berdasarkan Keputusan Gubernur DIY Nomor 222/KEP/2013 tanggal 26 Agustus 2013 tentang Penetapan Sekolah Model Pendidikan Etika Berlalu Lintas. Disdikpora DIY dan Ditlantas Polda Yogyakarta juga berkolaborasi dalam memeberikan sosialisasi kepada guru PKn agar dapat mengintegrasikan pendidikan etika berlalu lintas dalam kurikulum dan pembelajaran di kelas. Sementara itu, sekolah dan kepolisian secara rutin berkolaborasi dengan melaksanakan kegiatan sosialisasi pendidikan etika berlalu lintas dan bimbingan serta penyuluhan kepada siswa yeng terlambat sekolah.

Namun demikian dalam kolabirasi tersebut masih terdapat berbagai kendala. Oleh karena itu penulis memberikan sejumlah rekomendasi yaitu: 
1. Rekrutmen relawan dari gerakan pramuka, PMI dan PMR untuk terlibat dalam kegiatan SSDP.

2. Penegakan aturan bagi siswa pengendara sepeda motor yang belum memiliki SIM berupa peringatan tertulis.

3. Pengawasan dan pelarangan usaha persewaan parker kendaraan bermotor di luar sekolah.

4. Peningkatan kuantitas dan kualitas moda transportasi publik khususnya bis kota.

\section{Daftar Pustaka}

Ansell, Chriss \& Gash, Allison (2007), Collaborative Governance: Theory and Practice, London, Oxford University Press

Donahue, John (2004). On Collaborative Governance, Working Paper No 2, March 2004, John F Kennedy School of Government, Harvard University.

Peraturan Gubernur DIY No. 54 tahun 2011 tentang Pendidikan Etika Berlalu Lintas Pada Satuan Pendidikan.

Peraturan Walikota Yogyakarta Nomor 40 Tahun 2012 tentang Pelaksanaan Pendidikan Etika Berlalu Lintas di Kota Yogyakarta.

Radar Jogja. (2013). Tekan Kecelakaan di Kalangan Pelajar (http://www.radarjogja.co.id/berita/utama/24129-tekan-kecelakaan-di-kalanganpelajar.html diakses 4 Oktober 2013 pukul 13.35 WIB).

Sugiyono. (2010). Metode Penelitian Kuantitatif Kualitatif dan R\&D. Bandung:Alfabeta.

Undang-Undang No. 22 Tahun 2009 tentang Lalu Lintas dan Angkutan Jalan.

Wahyudi Kumorotomo ( 2013). Etika Administrasi Negara. Jakarta: PT Raja Grafindo Persada.

(http://www.seputarpengetahuan.com/2015/10/15-pengertian-etika-menurut-para-ahliterlengkap.html

etika-profesi.blogspot.co.id (http://www.salamedukasi.com/2014/09/etika-dan-tata-cara-berlalulintas-di.html 